OPEN ACCESS

Edited by:

Lin Zhang,

Hubei University of Chinese Medicine

China

Reviewed by:

Yang Wang,

Hebei Normal University, China

Zhu Wanlong,

Yunnan Normal University, China

*Correspondence: Eran Levin

levineran1@gmail.com

Specialty section:

This article was submitted to

Ecophysiology,

a section of the journal

Frontiers in Ecology and Evolution

Received: 08 August 2021 Accepted: 13 September 2021

Published: 05 October 2021

Citation:

Volov M, Cohen N, Bodner L, Dubiner S, Hefetz A, Bouchebti S and Levin E (2021) The Effect of Climate and Diet on Body Lipid Composition in the Oriental Hornet Nespa

orientalis).

Front. Ecol. Evol. 9:755331. doi: 10.3389/fevo.2021.755331

\section{The Effect of Climate and Diet on Body Lipid Composition in the Oriental Hornet (Vespa orientalis)}

\author{
Mika Volov, Nitzan Cohen, Levona Bodner, Shahar Dubiner, Abraham Hefetz, \\ Sofia Bouchebti and Eran Levin*
}

School of Zoology, Faculty of Life Sciences, Tel-Aviv University, Tel Aviv, Israel

Fatty acids (FA) are the primary metabolic fuel for many organisms and the fundamental component of membranes of all living organisms. FAs can be saturated (SFA), monounsaturated (MUFA), or polyunsaturated (PUFA). PUFA are not synthesized by most animals and are considered as essential nutrients. We examined the effect of climate on the saturation level of polar (mostly membranal) and neutral lipids in the body of the Oriental hornet (Vespa orientalis) from two extreme climatic zones: Mediterranean high elevation; and hot arid desert. In contrast to previous reports, the environmental temperature was shown to affect the hornet colonies' thermal environments. The hornets nonetheless maintained their colony temperature within a narrow range. Analyses of the hornets' unsaturation levels of polar and non-polar body lipids revealed caste differences: gynes and males contained less unsaturated lipids than workers. However, there were no differences in the respective castes between the two different climate zones tested. Experimentally manipulating the diet of queenless hornet colonies to a high Omega-3 diet (salmon) or a high Omega-6 diet (crickets) had only a minor effect on the worker-born males' lipid composition. Although salmon-fed males had a higher Omega-3 content than cricket-fed ones, the proportion of these fatty acids was still low (below 1\%). Cricket-fed males had significantly higher levels of Omega-6 than salmon-fed males. Our data show that the specific lipid composition of the hornet body is highly regulated and deficient in essential PUFA, even under different climates or high Omega-3 or Omega-6 PUFA diet. PUFA, especially Omega-3, is considered to have a beneficial effect on physiological processes. Our finding that these FA, when common in the diet, are almost absent in the body raises questions about how they affect animals' physiology.

Keywords: fatty acids, nutrition, climatic gradient, hornet (Vespa), Omega-3 fatty acids

\section{INTRODUCTION}

Fatty acids (FA) are essential macronutrients, precursors in various biological processes, and key components in living cell membranes (De Carvalho and Caramujo, 2018; Hulbert, 2021). FA can be saturated (SFA), monounsaturated, with one double bond (MUFA), or polyunsaturated with two or more double bonds (PUFA) (Wallis et al., 2002). The unsaturation level of FA in cellular membranes strongly affects their fluidity, flexibility, and selective permeability (Hulbert and Abbott, 2012). FA play an important physiological role in homeostasis and physiological functioning of tissues 
(Hazel, 1995; De Carvalho and Caramujo, 2018; Giri et al., 2018) and can directly affect membrane protein functions (Hulbert and Else, 1999; Hulbert et al., 2002), glucose metabolism (Clarke, 2000), and muscle function during high-performance activities (Peoples and McLennan, 2010; McWilliams et al., 2020). PUFA affect many cellular processes in animals, including modulation of ion channels and carrier activities of membrane-associated enzymes, regulation of gene expression, endocytosis/exocytosis, and defense against pathogens survival pathogen defense (Wallis et al., 2002; Pamplona, 2008). PUFA are traditionally divided into two different groups, depending on the position of the first double bond away from the Omega end of the carbonic chain-Omega 3 (n-3) or Omega 6 (n-6) (Hulbert, 2021). Omega3 PUFA are commonly found in marine ecosystems, especially in cold water, and are involved in learning and enhanced brain function in vertebrates and invertebrates (Arien et al., 2015; Dyall, 2015). Omega-6 PUFA are common in plants and terrestrial animals; they are precursors of prostaglandins and are involved in mitigating the inflammatory process (De Carvalho and Caramujo, 2018). Most animals lack the respective desaturase enzymes commonly found in plants and microorganisms (but see Cripps et al., 1986). Consequently, they must acquire both the $n-6$ and $n-3$ polyunsaturated FA from their diet or gut microbes (Hulbert et al., 2002). Accordingly, various studies have suggested that the composition of animal body FA reflects their diet (McKenzie, 2001; Pierce et al., 2005; Lemieux et al., 2008; Levin et al., 2013; Lehtovaara et al., 2017; McWilliams et al., 2020).

An experimental increase in PUFA content in the diet of different animals was shown to modulate their tissue composition and physiology. For example, a high PUFA diet was shown to lead to a higher basal metabolic rate (BMR) in several mammal species (Savage and Goldstone, 1965; Pan and Storlien, 1993; Takeuchi et al., 1995; Ayre and Hulbert, 1996). The percentage of PUFA in mammalian muscles was correlated with high muscle performance and a reduced energetic cost of high endurance exercise (Ruf et al., 2006; McWilliams et al., 2020). At the other extreme, in hibernating animals residing in cold climates, a high proportion of dietary PUFA prolonged torpor and lowered body temperatures and metabolism during hibernation, improving survival rate (Geiser et al., 1994; Ruf and Arnold, 2008). Additionally, PUFA may also play an important role in cold adaptation since species inhabiting cold climates generally possess more unsaturated membrane lipids than species occupying warmer environments (Logue et al., 2000).

A negative intraspecific correlation between latitude and saturation level of FAs has been reported in several cultivated plants. For example, PUFA levels in rice increased, and SFA and MUFA decreased, along a south to north latitudinal gradient of 12 degrees in Japan (Kitta et al., 2005). A similar pattern was observed in sunflowers and chia in Spain and South America (Ayerza, 2009), and temperature was suggested as the main environmental factor affecting FA composition in these species. Linder (2000) indicated that the seed oils of higherlatitude plants have proportionately more unsaturated fatty acids than those of lower-latitude plants (Linder, 2000). Finally, in a recent analysis of the lipid composition of 747 plants, a negative correlation was found between latitude and saturation (Zhang et al., 2015).

Based on all the above, PUFA in the ecosystem almost solely originate from the primary producers. Therefore, we hypothesized that climate and the availability of these essential fatty acids in the food web should also be correlated in the higher trophic levels. We expected to find higher proportions of PUFA in the environment and in the bodies of animals living in colder environments, and lower ratios in animals inhabiting warmer climates. This possible correlation between temperature and PUFA proportions may affect animals' physiology and environmental adaptation at all trophic levels. Here, we tested our hypothesis using the Oriental hornet (Vespa orientalis). $V$. orientalis is a relatively large hornet that establishes annual colonies in the spring in underground cavities, comprising up to several thousand individuals by the end of summer (Ishay, 1976; Dubiner et al., 2021). V. orientalis is well adapted to aridity and is the only member of the genus Vespa found in arid and warm habitats (Carpenter et al., 2013). We chose this species to test our hypothesis because it is distributed along a large climatic gradient and is a generalist predator with a high trophic level. It is a eusocial insect that establishes large colonies, in which the nests are maintained at a relatively constant temperature of $28^{\circ} \mathrm{C}$ (Ishay and Barenholz-Paniry, 1995). Thus, the FA in newly eclosed hornets that have developed under different climates should originate from their diet rather than being directly related to the ambient temperature. We further suggest that the adult hornets acquire their essential FA mainly from their diet during the larval stage. Adult hornets feed mainly on carbohydrates and free amino acids, which they use primarily for energy production and not fat accumulation (Hunt, 1991). Finally, we hypothesized that the FA composition in the hornets from the two polar climates should result only from the composition of their diet. We posit that the FA in prey collected by the hornets should be more unsaturated in the high-elevation, low-temperature climate. Moreover, since workers live only from spring to autumn while queens survive throughout the winter, we hypothesized that queens will accumulate more PUFA in their tissues than workers in order to support their lowered body temperature in winter.

\section{MATERIALS AND METHODS}

In May-September 2019, we located colonies of Oriental hornets in two different climatic regions of Israel, separated by $100 \mathrm{~km}$, along the north-south climatic gradient of the northern part of the Great Rift Valley. The northern location constitutes a Mediterranean high altitude habitat (900 m above sea level) with $800 \mathrm{~mm}$ of annual precipitation and occasional snow in winter. The southern area, by the Dead Sea (400 m below sea level), is a hot and dry desert with less than $70 \mathrm{~mm}$ annual precipitation (Figure 1). Previous studies have reported apparent phenotypic differences among populations along the steep climate gradient over a relatively short distance that characterizes Israel (e.g., in antlions and sparrows; Scharf et al., 2008; Cohen and Dor, 2018).

Colonies of Oriental hornets were located by following workers drinking at a water source back to their nest (they fly 


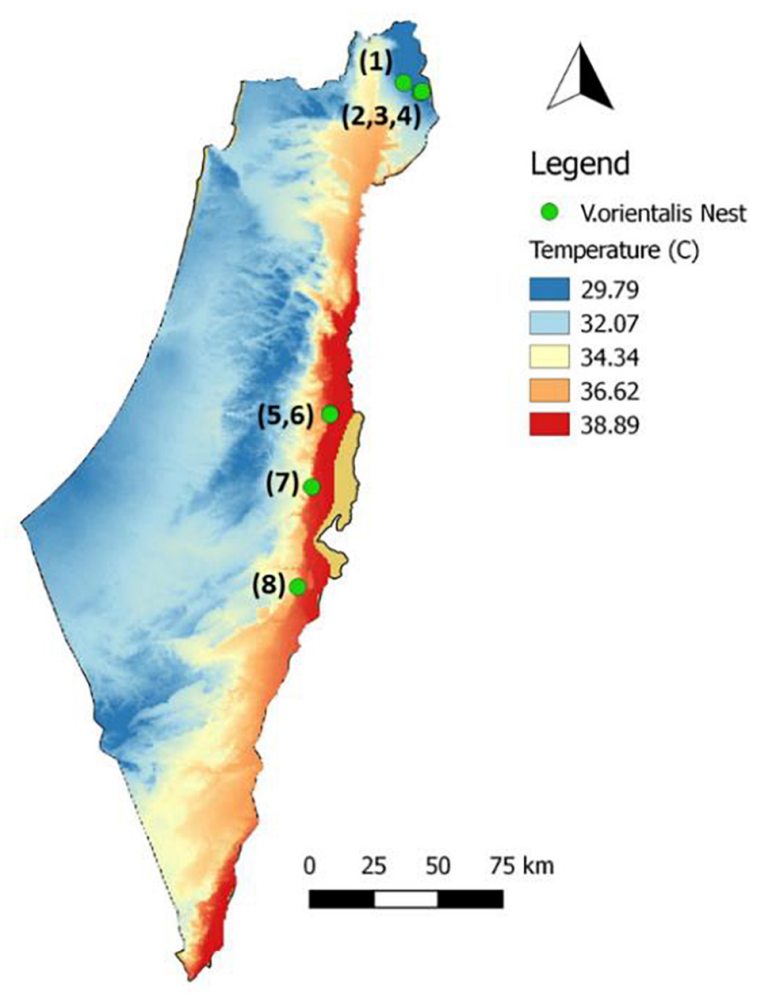

FIGURE 1 | Nests monitored and collected along the climatic gradient (1-4: north; 5-8: south). The temperature on the map is the average for the maximum daily temperature in August.

back in a direct transect). Temperature data loggers with external probes (Thermadata, United Kingdom, Accuracy $\pm 0.5^{\circ} \mathrm{C}$ ) were tunnelled into the center of six nests in the north of the country and three in the south (Table 1). Another data logger was placed $2 \mathrm{~m}$ above ground in the shade to record air temperatures next to each colony. The temperature was recorded every $30 \mathrm{~min}$ for 4-10 weeks. The temperature probes were destroyed in four of six colonies in the north, two by the hornets and two by European badgers (Meles meles).

At the end of the season (October), eight colonies (four from each climatic zone) were excavated, and the combs containing larvae and pupae were collected. Adult workers were collected from the excavated colonies by hand net, kept in a large sealed container, and frozen in the laboratory $\left(-80^{\circ} \mathrm{C}\right)$. The larvae and eggs were removed from the combs, and the pupae were kept in a temperature-controlled room $\left(28^{\circ} \mathrm{C}\right)$. Eclosed workers, gynes, and males were collected daily, placed in individual tubes, frozen, and stored at $-80^{\circ} \mathrm{C}$ until lipid analysis. All collections were performed under permit 2019/42252 from the Israel Nature and Parks Protection Authority.

\section{Fatty Acid Analysis}

We extracted the lipids separately from the abdomen and the thorax of the hornets, as the thorax contained mainly muscles and the abdomen contained fat storage and different organs
(Haddad et al., 2007; Hulbert et al., 2014). The body parts (thorax and abdomen) were each placed separately in a $4 \mathrm{ml}$ glass tube with $3 \mathrm{ml}$ chloroform-methanol solution (2:1), with $1 \mathrm{mg} / \mathrm{ml}$ of tridecanoic acid (C13:0, Sigma-Aldrich Corp.) as internal standard (Folch et al., 1957; Giri et al., 2018).

Total lipids from both the whole thorax (mainly flight muscle) and whole abdomen were extracted by homogenizing the tissues in 2:1 chloroform: methanol (v/v, Folch et al., 1957) and completing three cycles of shaking and centrifugation (10 $\mathrm{min}$, $\left.2,000 \mathrm{rpm}, 23^{\circ} \mathrm{C}\right)$. Before the last cycle, $1 \mathrm{ml}$ of $0.9 \% \mathrm{NaCl}$ was added to help remove any aqueous contaminants. The organic phase containing the lipids was collected using a Pasteur pipette into a clean $4 \mathrm{ml}$ vial and dried under nitrogen (Cerkowniak et al., 2013; Rodríguez et al., 2018). To separate lipids of different polarities from the flight muscle samples, the total lipids from the thorax were resuspended in $100 \mu \mathrm{l}$ chloroform and loaded onto solid-phase extraction columns (Supelclean $1 \mathrm{ml}$, 100 mg LC-NH2; Sigma-Aldrich; Israel). Sequential elution using solvents of increasing polarity, i.e., isopropyl ether: acetic acid (98:2 v/v), chloroform: isopropanol (3:2 v/v), and methanol, separated among neutral lipids, non-esterified fatty acids, and phospholipids (Maillet and Weber, 2006; Rodríguez et al., 2018). Fatty acids (both polar and non-polar) were trans-esterified using BF3 (17\% in methanol, Sigma-Aldrich; Israel) as suggested by Rule (Rule, 1997).

Initial FA analyses were performed by GC/MS (Agilent 5977) equipped with a DB-5MS UI column. The GC injector was maintained at $250^{\circ} \mathrm{C}$, and the oven temperature was programmed from $60(1 \mathrm{~min}$ hold $)$ to $300^{\circ} \mathrm{C}$ at $10^{\circ} \mathrm{C} / \mathrm{min}$ and held at the final temperature for $15 \mathrm{~min}$ (total run time $40 \mathrm{~min}$ ). The ionization mode was electron impact $(70 \mathrm{eV})$. The mass selective detector was operated in the scan mode between 40 and 600 AMU. Compounds were identified by their mass fragmentation, matched with mass spectra available on a NIST database, and compared with authentic standards (Sigma-Aldrich, Israel). For quantitative analyses, samples were analyzed in a Varian-3900XL gas chromatograph (GC-FID) equipped with a silica column (Varian, VF-5ms, $30 \mathrm{~m} \times 0.25 \mathrm{~m}, \mathrm{DF}=0.25$ ). Samples were run under the same temperature program as above. FA were identified by retention times and compared with those obtained in the GC/MS run and authentic standards. To ensure the correct identity of the compounds by their retention time, the same sample was run by both GC and GC/MS. Relative compound quantification was achieved by peak integration using Galaxie 1.9 software.

\section{Controlled Feeding Experiment}

An Oriental hornet colony was collected from Tel-Aviv University, Tel Aviv, Israel, in August 2019. The workers, larvae, and queen were removed from the comb cells, leaving only the worker pupae. The comb was then split into two equal parts, each containing 40 worker pupae, which were individually glued onto the ceiling of a wooden box $(330 \times 330 \times 150 \mathrm{~mm})$. Each box was placed in a separate outdoor netted cage $(4 \times 6 \times 2 \mathrm{~m})$. Eclosed workers in these queenless groups were free to leave their box and forage freely inside the netted cage. The hornets had access to water and nest-building materials (paper, dry plants, and soil). 
TABLE 1 | Position of the five colonies with temperature loggers.

\begin{tabular}{|c|c|c|c|c|}
\hline Zone & Location & Elevation (sea level) & $\mathbf{N}$ & $\mathbf{E}$ \\
\hline \multirow[t]{3}{*}{ Dead sea } & E. Gedi & -175 & 31.27 & 35.23 \\
\hline & K. south & -271 & 31.45 & 35.27 \\
\hline & K. north & -263 & 31.45 & 35.27 \\
\hline \multirow[t]{2}{*}{ Golan Heights } & E. Pahem & +696 & 32.58 & 35.49 \\
\hline & A. Habashan & +904 & 33.02 & 35.49 \\
\hline
\end{tabular}

Elevation in the Dead Sea area is below sea level.

Both groups received (ad lib) inverted sugar water (60\%), fresh fruits (grapes, mango, melon), but a different protein and fatty acid source. In one cage, we supplied the hornets with house crickets (Acheta domestica) rich in n-6 PUFA (Grapes et al., 1989), and in the second cage, we provided them with Atlantic salmon (Salmo salar), rich in n-3 PUFA (Sprague et al., 2016). Food items were replaced every other day. In the absence of a queen, the workers in both colonies rapidly developed their ovaries and laid unfertilized eggs that developed into males, which eclosed after 7 weeks. The newly eclosed males were frozen at $-80^{\circ} \mathrm{C}$ until lipid extraction and analysis, as described above. We also analyzed the fatty acids in both crickets and salmon to verify their lipid composition.

\section{Statistical Analysis}

We ran Kruskal-Wallis $H$-tests (followed by Dunn post-hoc) to compare abdomen and thorax samples' fatty acid unsaturation between castes and colonies, and Mann-Whitney $U$-tests to compare between the two feeding trials (unsaturation and $n$ 6 vs. $-n-3)$. Statistically significant defined as $p<0.05$. We performed principal component analyses (PCAs) to compare abdomen and thorax samples' fatty acid composition between castes, colonies, and diet. Data for PCA were log-transformed and scaled by centering the mean and dividing by the standard deviation of each variable to give similar weight to each component. Data analysis and visualization were done using Excel 2016 (Microsoft Office), JMP ${ }^{\circledR}$, Version 15. SAS Institute Inc., Cary, NC, 1989-2021, and MetaboAnalyst (version 5.0, McGill University, Montreal, QC, Canada).

\section{RESULTS}

\section{Colony Temperature}

The Oriental hornets did not maintain their nest at $28^{\circ} \mathrm{C}$ (as previously considered), but were nonetheless highly affected by the ambient temperature (Spearman rank correlation, Ein Gedi$r=0.74 p<0.05$, Kalya south- $r=0.56$. $p<0.05$, Kalia North$r=0.832 p<0.05$, Alonei Habashan- $r=0.342 p<0.05$, Ein Phaem- $r=0.95 p<0.05)$. Colony temperatures in the Dead Sea area were more tightly regulated than those by the hornets in the north. While the ambient temperature at the Dead Sea rose above $40^{\circ} \mathrm{C}$ almost every day during summer, and surface temperature could easily reach $60^{\circ} \mathrm{C}$, colony temperatures in all nests never exceeded $37^{\circ} \mathrm{C}$. In both areas, the average temperature inside the nest was maintained within a narrow range compared to the larger environmental temperature fluctuations (Table 2).

\section{Fatty Acid Analysis}

Five fatty acids were dominant in the hornet, accounting for more than $95 \%$ of the total FA content (see the Supp. Mat. for the complete list): palmitic acid (C16:0), palmitoleic acid (C16:1), stearic acid (C18:0), oleic acid (C18:1), and linoleic acid (C18:2). Oleic acid was the most abundant of the five (37-73\%). n-3 PUFA were not detected in the polar fraction of the workers' thorax, except for trace amounts in the workers from the Wadi Ashalim colony, in the extreme desert (0.1-0.2\%). PUFA n-6 FA, mainly linoleic acid, were higher than PUFA $n-3$ (4-6\%) but did not differ between the two climatic regions (thorax: $Z=0.12716, p=0.898$; abdomen: $Z=-0.399, p=0.689$ ).

We compared the total abdominal FA and thoracic polar FA between castes in hornets from all colonies (except Ashalim, where only workers were collected) using PCA (Figure 2). We found a clear distinction in abdominal fatty acids between workers and the other castes, mainly due to the workers' high content of linoleic and palmitoleic acids, in addition to several less common acids present at low concentrations. PCA of thoracic polar FA derived from phospholipids showed an even more distinct separation between workers and gynes, with males being highly variable intermediates.

PCA of abdominal FA from workers showed a separation between colonies. This separation was not according to the climatic region in any of the principal components (Figure 3), however, but mainly due to the very low abundance of a few rare FA (see Supplementary Table 1). This difference disappeared entirely in the analysis of the thoracic FA (Figure 3), in which the colonies were essentially indistinguishable.

Worker FA were dominated by MUFA (abdomen: $74.3 \pm 4.4 \%$, thorax: $81.5 \pm 8.5 \%$ ). A comparison of the degree of unsaturation between northern and southern hornet workers FAs revealed no difference between the two regions [thorax SFA $(Z=-0.894, p=0.371)$, MUFA $(Z=0.479, p=0.6313)$, PUFA $(Z=-0.105, p=0.915)$; abdomen SFA $(Z=0.140, p=0.887)$, MUFA $(Z=-0.093, p=0.925)$, PUFA $(Z=-0.047, p=0.962)]$.

Worker FA of all degrees of saturation differed significantly from the other castes, being lower in SFA (Kruskal-Wallis for thorax: $\chi^{2}=54.4, p<<0.001$; for abdomen: $\chi^{2}=47.6$, $p<<0.001$ ), and higher in MUFA (thorax: $\chi^{2}=44.8$, $p<<0.001$; abdomen: $\left.\chi^{2}=49.3, p<<0.001\right)$, and in PUFA (thorax: $\chi^{2}=14.8, p=0.0006$; abdomen: $\chi^{2}=39.2, p<<0.001$ ). Gynes and males differed from each other only in PUFA, which 
TABLE 2 | Average ( \pm SE) of mean, minimum and maximum temperature inside and above the nest and mean seasonal temperature.

\begin{tabular}{|c|c|c|c|c|c|c|c|}
\hline \multirow[t]{2}{*}{ Zone } & \multirow[t]{2}{*}{ Location } & \multicolumn{3}{|c|}{ Nest $\left({ }^{\circ} \mathrm{C}\right)$} & \multicolumn{3}{|c|}{ Air $\left({ }^{\circ} \mathrm{C}\right)$} \\
\hline & & Mean & Min & Max & Mean & Min & Max \\
\hline \multirow[t]{3}{*}{ Dead sea } & E. Gedi & $35.02 \pm 0.9$ & $34.42 \pm 0.8$ & $35.52 \pm 0.9$ & $32.87 \pm 1.6$ & $29.35 \pm 1.50$ & $36.49 \pm 2.2$ \\
\hline & K. south & $33.96 \pm 1.1$ & $32.37 \pm 1.1$ & $34.95 \pm 1.1$ & $31.83 \pm 1.7$ & $27.62 \pm 1.40$ & $37.48 \pm 2.2$ \\
\hline & K. north & $33.83 \pm 1.9$ & $32.95 \pm 0.9$ & $34.35 \pm 1$ & $31.83 \pm 1.7$ & $27.62 \pm 1.40$ & $37.48 \pm 2.2$ \\
\hline \multirow[t]{2}{*}{ Golan heights } & E. Pahem & $27.97 \pm 0.9$ & $26.41 \pm 1$ & $29.77 \pm 1$ & $24.39 \pm 1.3$ & $19.35 \pm 1.07$ & $30.57 \pm 2.2$ \\
\hline & A. Habashan & $27.54 \pm 2.1$ & $24.68 \pm 2$ & $31.61 \pm 2.5$ & $22.40 \pm 2.4$ & $17.27 \pm 1.94$ & $29.05 \pm 3$ \\
\hline
\end{tabular}
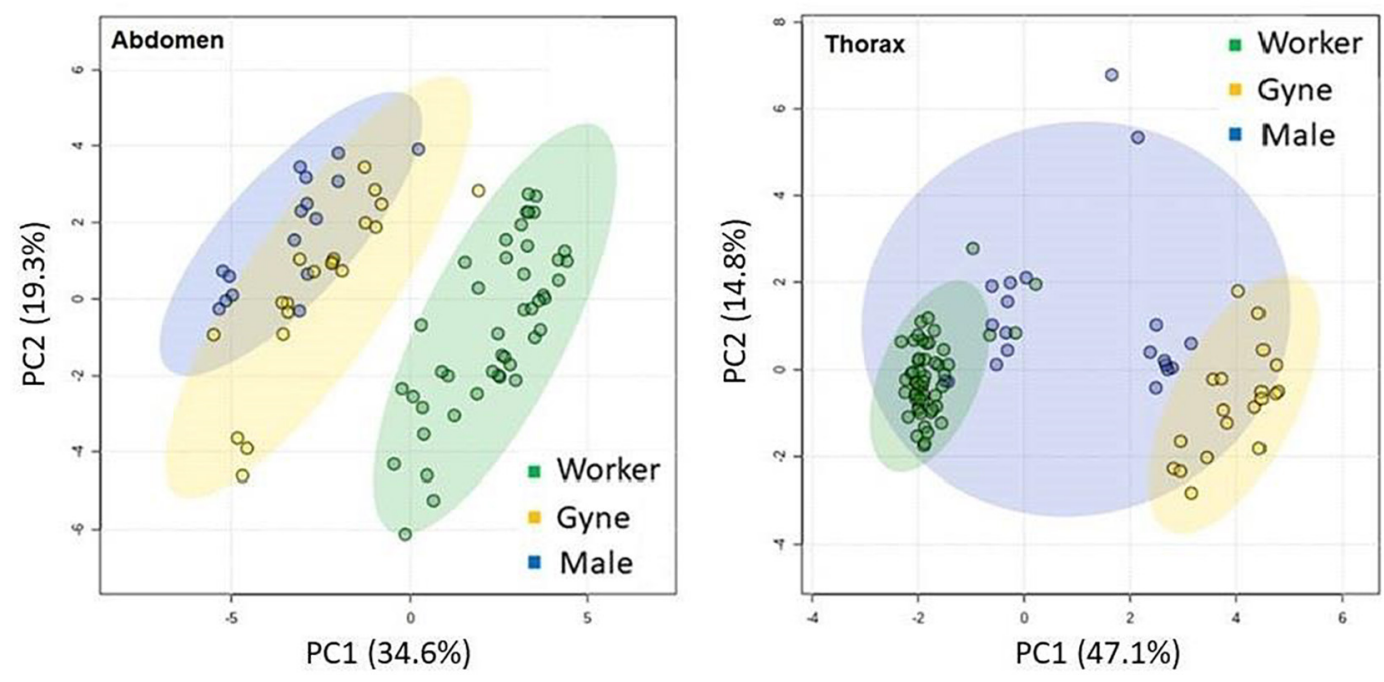

FIGURE 2 | Principal component analysis of fatty acids in both total lipids of the abdomen and polar lipids from the thorax of the three hornet castes (workers $n=44.58$, Gynes $n=20.24$, Males $n=16.20$ for thorax and abdomen, respectively).

were lower for gynes (Dunn post-hoc for thorax: $p=0.006$; for the abdomen: $p=0.018$, Figure 4).

There was no apparent difference in the PCA between cricketfed male hornets (PUFA $n-6$ rich diet, 42\%) and salmon-fed ones (PUFA $n-3$ rich diet, $12.8 \%$ ) in the feeding manipulation trials (Figure 5). This was true for both abdominal and thoracic samples, even though the diet in both trials differed from that of wild males.

PUFA $n-3$ levels were higher in salmon-fed hornets than cricket fad ones (Mann-Whitney $U$-test: $Z=-2.196, p<0.05$ ) but were still very low, accounting for less than $0.5 \%$ of thorax FA composition. However, PUFA n- 6 were higher in cricket-fed hornets than the salmon fed ones $(Z=-1.757, p<0.05)$ and exceeded $10 \%$ of thorax FA content, a nearly fivefold increase from that of salmon-fed hornets (Figure 6).

\section{DISCUSSION}

We tested the hypothesis that climate affects the saturation level of FA in the environment and that such effects will be reflected at several trophic levels. We used the Oriental hornet as a model organism for our study as it inhabits various climates and has a broad dietary preference. Because Oriental hornets had been considered to regulate their colony temperature, we expected any change in their FA composition to be dietary derived. In contrast to our expectations and to earlier reports (Ishay and BarenholzPaniry, 1995; Plotkin et al., 2005), the colony temperatures in the northern part of Israel were affected by the environmental temperature. However, there seems to be an upper limit to the temperature that the hornets are able to support. In the Dead Sea's arid and hot region (mean $44^{\circ} \mathrm{C}$ in the shade), colony temperature was maintained at around $35^{\circ} \mathrm{C}$ and did not surpass $37^{\circ} \mathrm{C}$. We found no effect of environment on lipid saturation in the hornets' polar and neutral lipids. Food composition had a low impact on their lipid composition, even when artificially manipulated to an extreme composition in captivity. However, we did find differences in the lipid composition among the different castes. These findings suggest that lipid composition in hornets is highly conserved, even under extreme environmental and nutritional conditions.

\section{Temperature and Thermoregulation}

Changes in polar FA composition following thermal acclimation have been a central concept in thermal physiology, but the diversity in such changes among species living in different thermal environments is far less documented (Rodríguez et al., 2018). Various social insects regulate their colony temperature, 

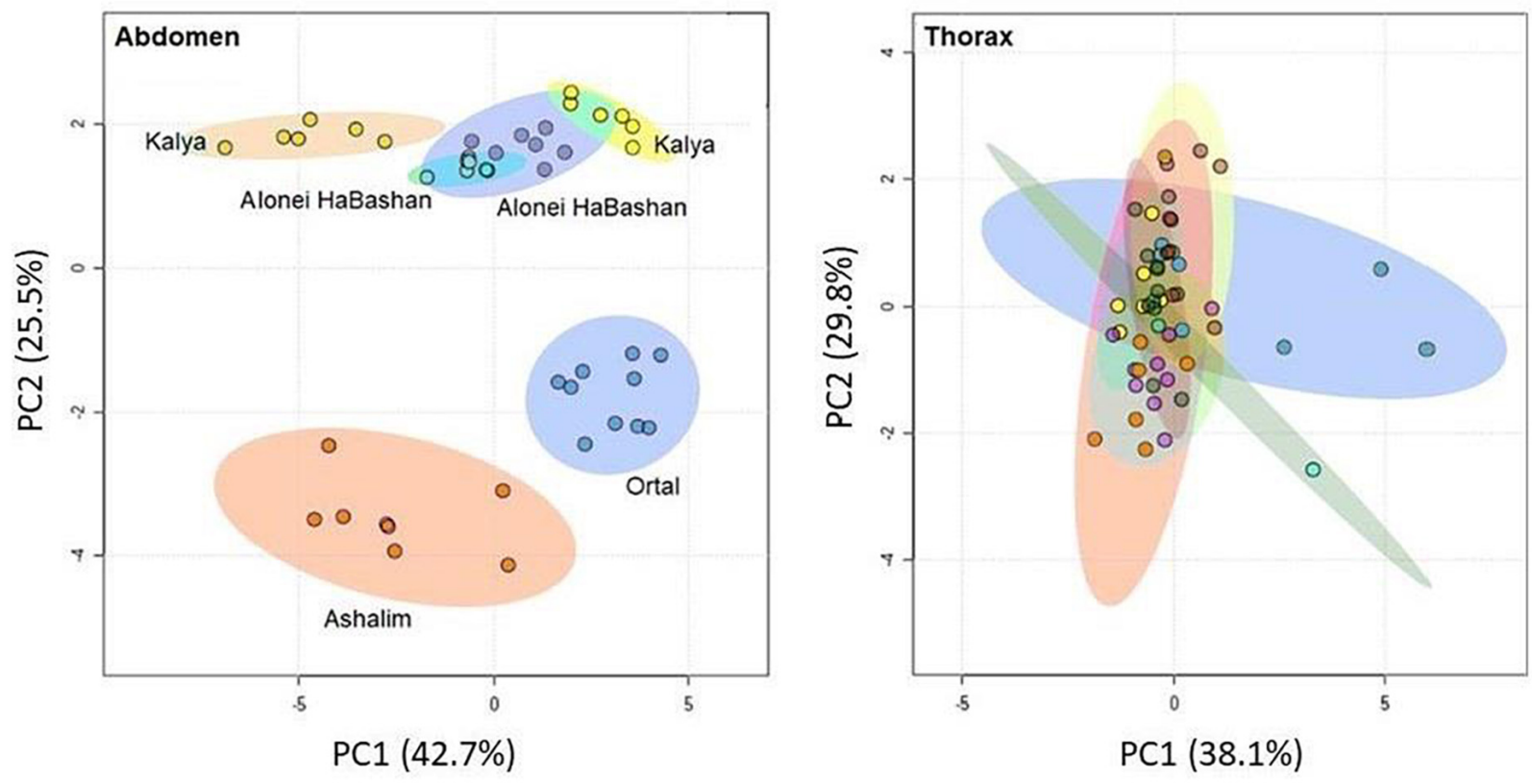

FIGURE 3 | Principal component analysis of fatty acids in both total lipids of the abdomen and polar lipids from the thorax of workers from different colonies. Northern colonies are presented in cold colors and southern colonies in warm colors (sample size: Ortal $n=9, \mathrm{~A}$. HaBashan a $n=7$, A. HaBashan b $n=4$, Kalya a $n=5$, Kalya b $n=6$, Ashalim $n=7$ ).

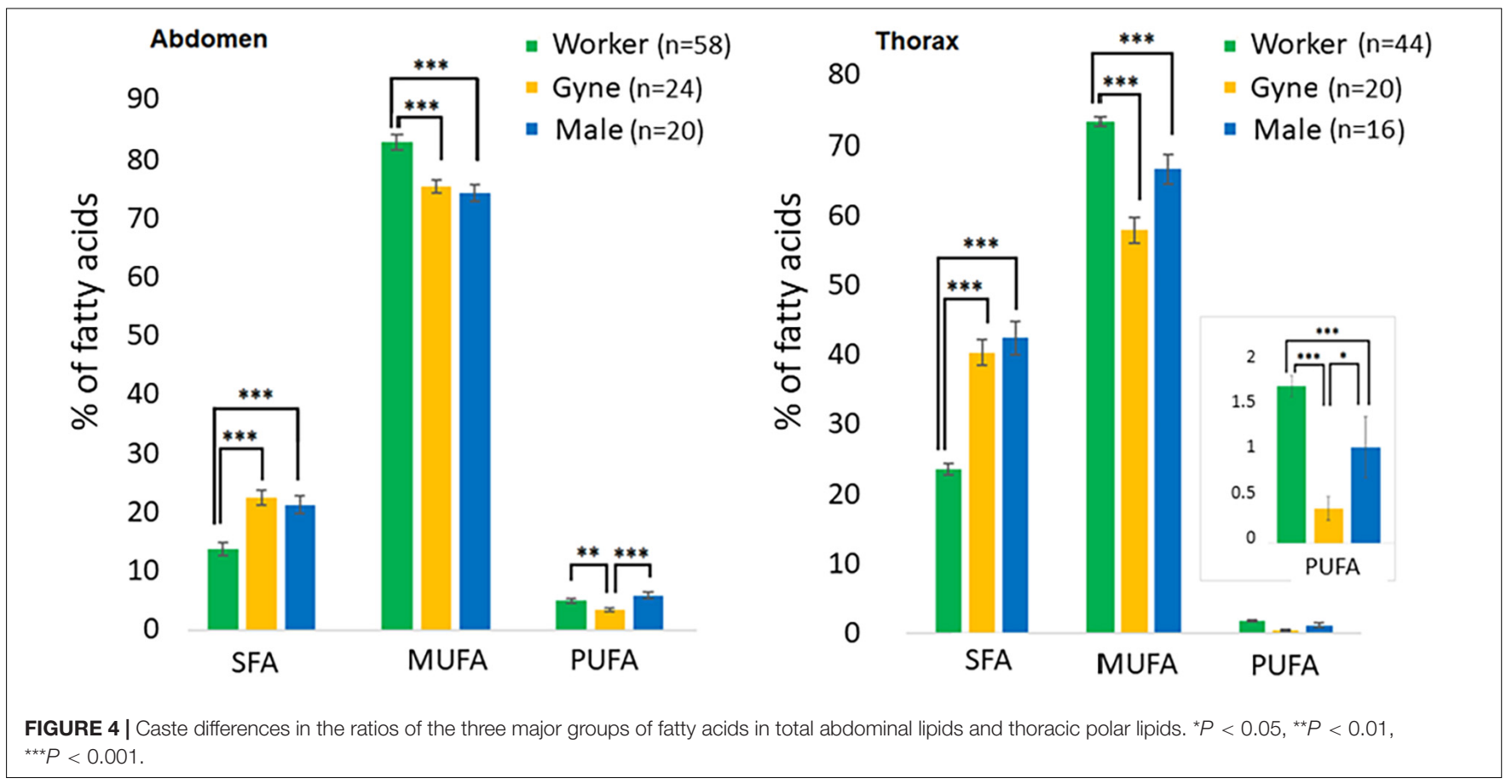

consistent with the "superorganism" theory (Seeley, 1989; Wilson and Sober, 1989). Honey bees, for example, maintain the temperature around their brood at $35^{\circ} \mathrm{C}$ (Simpson, 1961; Heinrich, 1981; Stabentheiner et al., 2010). Oriental hornets are at their peak of activity during late summer, with thousands of workers and larvae in the colonies. At this time of the year the hornets' main challenge lies in cooling down their colony, which they actively do by means of ventilation and evaporating water drops (Ishay and Barenholz-Paniry, 1995; Jones and Oldroyd, 2006). We found that while the hornet colony temperature in the two extreme climates differed from one another, it was primarily regulated to within a narrow range of temperatures, especially in 

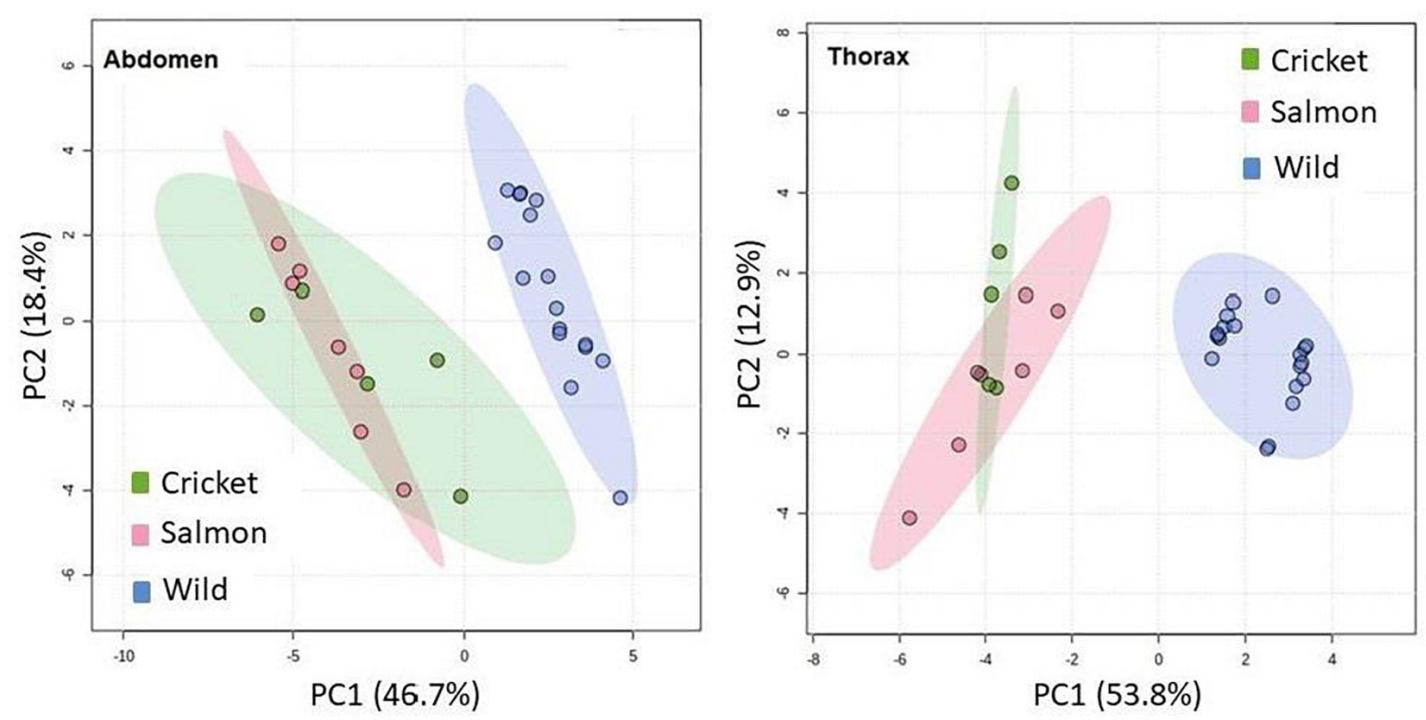

FIGURE 5 | Principal component analysis of fatty acids in both total lipids of the abdomen and polar lipids from the thorax of males fed as larvae with either salmon (pink, $n=7$ ), crickets (green, $n=5$ ), or natural diet collected in the field by workers (blue, $n=16$ ).
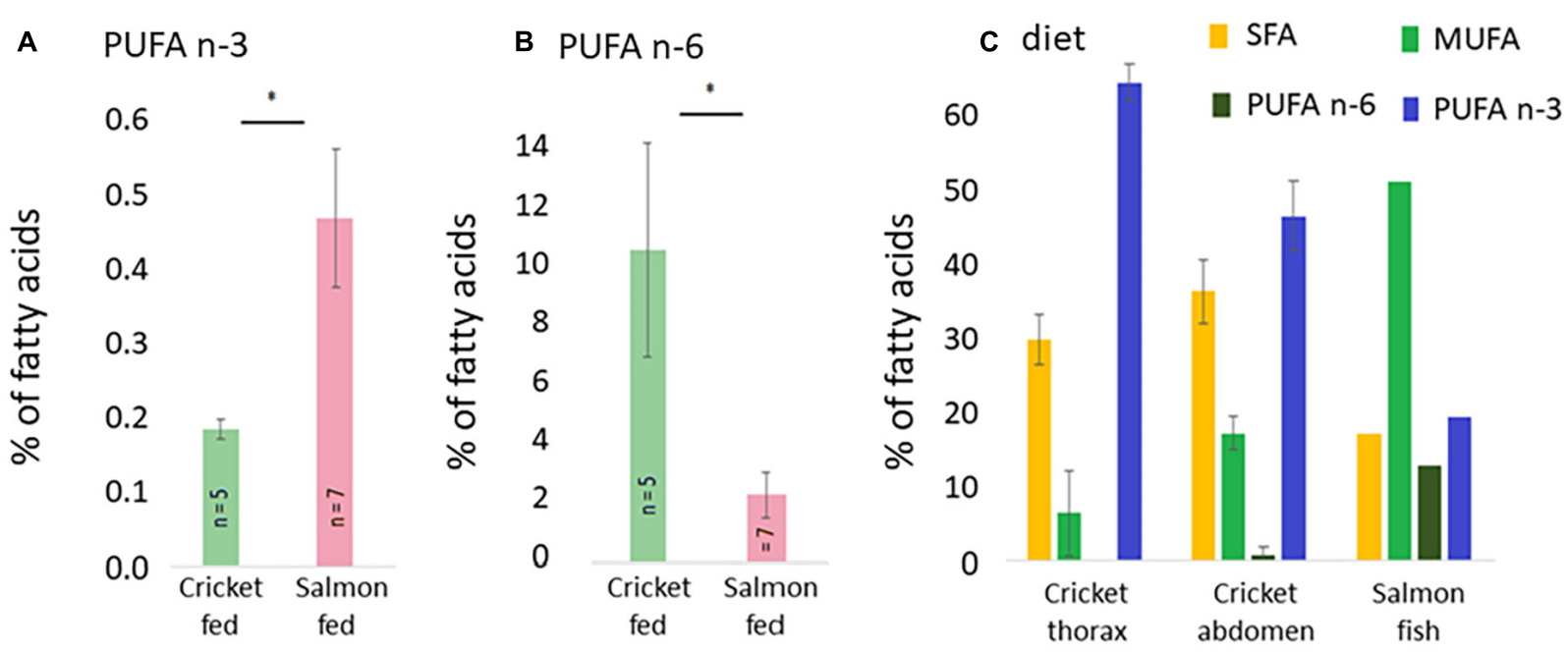

FIGURE 6 | $n$-3 polar lipids (A) and n-6 polar lipids (B) in the flight muscles of males reared on the two different diets (crickets or salmon), and the general composition of the two diets: crickets $(n=5)$ and salmon $(n=1)(\mathbf{C}) .{ }^{*} P<0.05$.

the upper limit of ambient temperature. No difference was found, however, in the hornets' polar and non-polar FA saturation levels. The FA composition for the hornets was highly conserved, with very high MUFA (55.9-81.5\%), low levels of PUFA (0.4-11.9\%), and almost no Omega-3 PUFA (below $0.5 \%$ of total PUFA).

MUFA are the primary FA in the Oriental hornet lipids, comprising about $80 \%$ of the FA in the workers' flight muscles. Oleic acid (18:1 n-9) is the dominant FA among these MUFA in all Oriental hornet castes. Animals efficiently synthesize oleic acid by adding a double bond to stearic acid (Michaud and Denlinger, 2006; Hulbert et al., 2014). The different desaturases responsible for this process are highly regulated in animals, and their expression and activity are affected by environmental factors, including temperature (Stukey et al., 1990; Murata and
Wada, 1995; Bennett et al., 1997; Los and Murata, 1998). The double bond in oleic acid reduces its melting point to around $13^{\circ} \mathrm{C}\left(69.3^{\circ} \mathrm{C}\right.$ for stearic acid, 18:0). Incorporating oleic acid into biological membranes affects the phase transition at low temperatures (Silvius, 1982). It is $40-80$ times more resistant to peroxidation than linoleic (18:2) or linolenic (18:3) acids, respectively (Holman, 1954). Different membranal proteins, including ATPases, optimize functioning in oleic acid-rich membranes (Starling et al., 1993). When combining oleic acid with palmitoleic acid (16:1 n-7), membranes can function in temperatures even below $10^{\circ} \mathrm{C}$ (Bennett et al., 1997; Bashan and Cakmak, 2005). These two FA are among the most common FA in different species of insects that undergo winter diapause (Stanley-Samuelson et al., 1988; Bashan and Cakmak, 2005; 
Michaud and Denlinger, 2006). The thermal environment of $V$. orientalis rarely falls below $20^{\circ} \mathrm{C}$ (except for diapausing queens). In other hymenopterans, the ratio of oleic acid was found to positively correlate with thorax temperature (Rodríguez et al., 2015, 2018). In two species of hibernating mammals preying on ants, a high level of oleic acid was found in their body prior to hibernation and was suggested to be the most common FA in these insects (Falkenstein et al., 2001; Levin et al., 2013). We suggest that $V$. orientalis's integration of oleic acid into their membranes reduces their susceptibility to oxidative damage, while maintaining an optimal fluidity for membrane functionality under the relatively high temperatures in which this species lives.

\section{Fatty Acid Composition of Storage and Polar Lipids}

Even when enriching the hornets' diet with Omega-3 or Omega6 , only low levels of these essential FA were recorded in the male's neutral and polar lipids, and the two treatments could not be separated according to the composition of their FA. However, the salmon diet significantly reduced the total PUFA in the males compared to the cricket diet and to the males in wild colonies. We suggest that PUFA are highly available in the hornets' diet in the wild, even if they are later found in very low ratios in their bodies (Haddad et al., 2007). It is unlikely that hornets selectively refrain from absorbing PUFA from food, and we suggest that these PUFA are either used as fuel or undergo a saturation process. The second option is intriguing, as to the best of our knowledge, such a pathway of saturation of body lipids is unknown in animals. The adaptive value of such selective fatty acid accumulation might reduce oxidative stress, as PUFA are much more sensitive to radical attack than MUFA or SFA (Pamplona et al., 2000; Hulbert et al., 2007). Recently, dietary lipids were found to negatively affect survival in bumble bees (Ruedenauer et al., 2020).

On the other hand, Omega-3 PUFA are essential for neuronal function in mammals and are suggested to be crucial for learning in honey bees (Arien et al., 2015). These FA were absent in phospholipids from the head of honey bees (Haddad et al., 2007), and in phospholipids from blowflies (Calliphora stygia) reared on fish (Kelly et al., 2014). Thus, their role in the animal body or the trade-off mechanism involved with this FA is unclear.

Caste specificity was demonstrated in the FA profile and saturation. This difference was significant for both the polar and neutral lipids. In Oriental hornets, although the queens are the only caste exposed to low ambient temperature, they displayed the lowest PUFA levels in both body (abdomen) and muscles. Such caste variation was also reported in honey bees (Haddad et al., 2007; Martin et al., 2019). In hornets, unlike bees, we are not aware of different compositions of food supplied to the gyne larvae during their development. We suggest that the difference in FA composition should be related to the difference in allocation of FA between the castes. The high FA saturation level in hornet queens partially agrees with the increased saturation level found in bee queens and the peroxidation theory (Haddad et al., 2007). The peroxidation theory suggests that the higher the saturation of lipids in the membranes of bee queens, the higher their longevity. In another hymenopteran queen - that of the carpenter ant, Levin et al. (2013) found a similar pattern of low levels of PUFA (Levin et al., 2013), which might also be related to these queens' remarkable longevity (up to 26 years Vonshak and Shlagman, 2009). The Oriental hornet queen lives for almost an entire year, whereas workers live for only a few weeks.

Climate affects the thermal environment of the Oriental hornet colony. However, they are able to maintain their colony temperature within a relatively narrow range. The lipid composition in the Oriental hornet remained highly conserved even under extreme climates and diet manipulations. We found significant differences in polar (assumed to be membrane originated) and non-polar lipid saturation levels between the different hornet castes. We suggest that a particular membrane composition is vital for the hornet's physiological functioning and that it is regulated to maintain this specific composition. The mechanism behind the regulation of FA saturation and composition offers an exciting subject for future studies.

\section{DATA AVAILABILITY STATEMENT}

The original contributions presented in the study are included in the article/Supplementary Material, further inquiries can be directed to the corresponding author/s.

\section{AUTHOR CONTRIBUTIONS}

EL: conceptualization, resources, supervision, and original draft writing. MV: conceptualization, data curation, and data analysis. NC: field data curation. SD: GC data curation and data analysis. LB: conceptualization, field data curation, and review and editing. AH: GC and GCMS data identification, resources, and review and editing. SB: data analysis, original draft writing, and visualization. All authors contributed to the article and approved the submitted version.

\section{FUNDING}

This research was supported by the ISF grant 1538/18 and a research grant from DSRI-Life in Extreme Conditions to EL.

\section{ACKNOWLEDGMENTS}

We would like to thank Tovit Simon and Aviv Amirav for their assistance with lipid extraction and identification. We thank Inon Scharf for reading and commenting on the ms and Ronit Zach for fruitful discussions.

\section{SUPPLEMENTARY MATERIAL}

The Supplementary Material for this article can be found online at: https://www.frontiersin.org/articles/10.3389/fevo.2021. 755331/full\#supplementary-material 


\section{REFERENCES}

Arien, Y., Dag, A., Zarchin, S., Masci, T., and Shafir, S. (2015). Omega-3 deficiency impairs honey bee learning. Proc. Natl. Acad. Sci. U.S.A. 112, 15761-15766. doi: $10.1073 /$ pnas. 1517375112

Ayerza, R. (2009). The seed's protein and oil content, fatty acid composition, and growing cycle length of a single genotype of chia (Salvia hispanica 1.) as affected by environmental factors. J. Oleo Sci. 58, 347-354. doi: 10.5650/jos.58. 347

Ayre, K. J., and Hulbert, A. J. (1996). Dietary fatty acid profile influences the composition of skeletal muscle phospholipids in rats. J. Nut. 126, 653-662. doi: $10.1093 /$ jn/126.3.653

Bashan, M., and Cakmak, O. (2005). Changes in composition of phospholipid and triacylglycerol fatty acids prepared from prediapausing and diapausing individuals of Dolycoris baccarum and Piezodorus lituratus (heteroptera: Pentatomidae). Ann. Entomol. Soc. Am. 98, 575-579. doi: 10.1603/00138746(2005)098[0575:cicopa]2.0.co;2

Bennett, V. A., Pruitt, N. L., and Lee, R. E. Jr. (1997). Seasonal changes in fatty acid composition associated with cold-hardening in third instar larvae of Eurosta solidaginis. J. Comparat. Physiol. B 167, 249-255. doi: 10.1007/s003600050071

Carpenter, J., Kojima, , J.-I., and Villemant, C. (2013). Phylogeny of hornets: a total evidence approach (Hymenoptera, Vespidae, Vespinae, Vespa). J. Hymenopt. Res. 32:1. doi: 10.3897/jhr.32.4685

Cerkowniak, M., Puckowski, A., Stepnowski, P., and Gołębiowski, M. (2013). The use of chromatographic techniques for the separation and the identification of insect lipids. J. Chromatogr. B 937, 67-78. doi: 10.1016/j.jchromb.2013.08. 023

Clarke, S. D. (2000). Polyunsaturated fatty acid regulation of gene transcription: a mechanism to improve energy balance and insulin resistance. Br. J. Nut. 83, S59-S66.

Cohen, S. B., and Dor, R. (2018). Phenotypic divergence despite low genetic differentiation in house sparrow populations. Sci. Rep. 8, 1-12. doi: 10.2307/ 2406496

Cripps, C., Blomquist, G. J., and de Renobales, M. (1986). De novo biosynthesis of linoleic acid in insects. Biochim. et Biophys. Acta (BBA) Lipids Lipid Metab. 876, 572-580. doi: 10.1016/0005-2760(86)90046-9

De Carvalho, C. C., and Caramujo, M. J. (2018). The various roles of fatty acids. Molecules 23:2583. doi: 10.3390/molecules23102583

Dubiner, S., Cohen, N., Volov, M., Hefetz, A., Seltzer, R., and Levin, E. (2021). The exocrine chemistry of the parasitic wasp Sphecophaga orientalis and its host Vespa orientalis: a case of chemical deception? Insects 12:2. doi: 10.3390/ insects 12010002

Dyall, S. C. (2015). Long-chain omega-3 fatty acids and the brain: a review of the independent and shared effects of epa, dpa and dha. Front. Aging Neurosci. 7:52.

Falkenstein, F., Kortner, G., Watson, K., and Geiser, F. (2001). Dietary fats and body lipid composition in relation to hibernation in free-ranging echidnas. J. Comparat. Physiol. B Biochem. Syst. Environ. Physiol. 171, 189-194. doi: $10.1007 / \mathrm{s} 003600000157$

Folch, J., Lees, M., and Stanley, G. S. (1957). A simple method for the isolation and purification of total lipides from animal tissues. J. Biol. Chem. 226, 497-509. doi: 10.1016/s0021-9258(18)64849-5

Geiser, F., McAllan, B., and Kenagy, G. (1994). The degree of dietary fatty acid unsaturation affects torpor patterns and lipid composition of a hibernator. J. Comparat. Physiol. B 164, 299-305. doi: 10.1007/bf00346446

Giri, S., Rule, D. C., and Dillon, M. E. (2018). Fatty acid composition in native bees: associations with thermal and feeding ecology. Comparat. Biochem. Physiol. Part A Mol. Integrat. Physiol. 218, 70-79. doi: 10.1016/j.cbpa.2018.01.013

Grapes, M., Whiting, P., and Dinan, L. (1989). Fatty acid and lipid analysis of the house cricket Acheta domesticus. Insect. Biochem. 19, 767-774. doi: 10.1016/ 0020-1790(89)90058-9

Hazel, J. R. (1995). Thermal adaptation in biological membranes: is homeoviscous adaptation the explanation? Annu. Rev. Physiol. 57, 19-42. doi: 10.1146/ annurev.ph.57.030195.000315

Haddad, L. S., Kelbert, L., and Hulbert, A. (2007). Extended longevity of queen honey bees compared to workers is associated with peroxidation-resistant membranes. Exp. Gerontol. 42, 601-609.

Heinrich, B. (1981). Energetics of honeybee swarm thermoregulation. Science 212, 565-566. doi: 10.1126/science.212.4494.565
Holman, R. T. (1954). Autoxidation of fats and related substances. Prog. Chem. Fats Other Lipids 2, 51-98. doi: 10.1016/0079-6832(54) 90004-x

Hulbert, A. (2021). The under-appreciated fats of life: the two types of polyunsaturated fats. J. Exp. Biol. 224:jeb232538.

Hulbert, A., and Else, P. L. (1999). Membranes as possible pacemakers of metabolism. J. Theor. Biol. 199, 257-274. doi: 10.1006/jtbi.1999.0955

Hulbert, A., Rana, T., and Couture, P. (2002). The acyl composition of mammalian phospholipids: an allometric analysis. Comparat. Biochem. Physiol. Part B Biochem. Mol. Biol. 132, 515-527. doi: 10.1016/s1096-4959(02)00066-0

Hulbert, A. J., and Abbott, S. K. (2012). Nutritional ecology of essential fatty acids: an evolutionary perspective Australian. J. Zool. 59, 369-379. doi: 10.1071/ zo11064

Hulbert, A. J., Kelly, M. A., and Abbott, S. K. (2014). Polyunsaturated fats, membrane lipids and animal longevity. J. Comparat. Physiol. B 184, 149-166. doi: 10.1007/s00360-013-0786-8

Hulbert, A. J., Pamplona, R., Buffenstein, R., and Buttemer, W. A. (2007). Life and death: metabolic rate, membrane composition, and life span of animals. Physiol. Rev. 87, 1175-1213. doi: 10.1152/physrev.00047.2006

Hunt, J. H. (1991). Nourishment and the evolution of the social vespidae. Soc. Biol. Wasps 426:450.

Ishay, J. (1976). Comb building by the oriental hornet (Vespa orientalis). Animal. Behav. 24, 72-83. doi: 10.1016/s0003-3472(76)80101-7

Ishay, J. S., and Barenholz-Paniry, V. (1995). Thermoelectric effect in hornet (Vespa orientalis) silk and thermoregulation in a hornet's nest. J. Insect Physiol. 41, 753-759. doi: 10.1016/0022-1910(95)00034-r

Jones, J. C., and Oldroyd, B. P. (2006). Nest thermoregulation in social insects Advances in insect. Physiology 33, 153-191. doi: 10.1016/s0065-2806(06) 33003-2

Kelly, M. A., Usher, M. J., Ujvari, B., Madsen, T., Wallman, J. F., Buttemer, W. A., et al. (2014). Diet fatty acid profile, membrane composition and lifespan: an experimental study using the blowfly (Calliphora stygia). Mech. Ageing Dev. 138, 15-25. doi: 10.1016/j.mad.2014.02.001

Kitta, K., Ebihara, M., Iizuka, T., Yoshikawa, R., Isshiki, K., and Kawamoto, S. (2005). Variations in lipid content and fatty acid composition of major nonglutinous rice cultivars in Japan. J. Food Composit. Anal. 18, 269-278. doi: 10.1016/j.jfca.2004.10.001

Lehtovaara, V., Valtonen, A., Sorjonen, J., Hiltunen, M., Rutaro, K., Malinga, G. M. et al. (2017). The fatty acid contents of the edible grasshopper Ruspolia differens can be manipulated using artificial diets. J. Insects Food Feed 3, 253-262. doi: 10.3920/jiff2017.0018

Lemieux, H., Blier, P., and Tardif, J.-C. (2008). Does membrane fatty acid composition modulate mitochondrial functions and their thermal sensitivities? Comparat. Biochem. Physiol. Part A Mol. Integ. Physiol. 149, 20-29. doi: 10. 1016/j.cbpa.2007.09.015

Levin, E., Yom-Tov, Y., Hefetz, A., and Kronfeld-Schor, N. (2013). Changes in diet, body mass and fatty acid composition during pre-hibernation in a subtropical bat in relation to npy and agrp expression. J. Comparat. Physiol. B 183, 157-166. doi: 10.1007/s00360-012-0689-0

Linder, C. R. (2000). Adaptive evolution of seed oils in plants: accounting for the biogeographic distribution of saturated and unsaturated fatty acids in seed oils. Am. Nat. 156, 442-458. doi: 10.2307/3079176

Logue, J. A., De Vries, A. L., Fodor, E., and Cossins, A. R. (2000). Lipid compositional correlates of temperature-adaptive interspecific differences in membrane physical structure. J. Exp. Biol. 203, 2105-2115. doi: 10.1242/jeb. 203.14.2105

Los, D. A., and Murata, N. (1998). Structure and expression of fatty acid desaturases. Biochim. et Biophys. Acta (BBA) Lipids Lipid Metab. 1394, 3-15. doi: 10.1016/s0005-2760(98)00091-5

Maillet, D., and Weber, J.-M. (2006). Performance-enhancing role of dietary fatty acids in a long-distance migrant shorebird: the semipalmated sandpiper. J. Exp. Biol. 209, 2686-2695. doi: 10.1242/jeb.02299

Martin, N., Hulbert, A. J., Brenner, G. C., Brown, S. H. J., Mitchell, T. W., and Else, P. L. (2019). Honey bee caste lipidomics in relation to life-history stage and the long life of the queen. J. Exp. Biol. 222, 1-12.

McKenzie, D. J. (2001). Effects of dietary fatty acids on the respiratory and cardiovascular physiology of fish. Comparat. Biochem. Physiol. Part A Mol. Integr. Physiol. 128, 605-619. doi: 10.1016/s1095-6433(00)00338-x 
McWilliams, S., Pierce, B., Wittenzellner, A., Langlois, L., Engel, S., Speakman, J. R., et al. (2020). The energy savings-oxidative cost trade-off for migratory birds during endurance flight. Elife 9:e60626.

Michaud, M. R., and Denlinger, D. L. (2006). Oleic acid is elevated in cell membranes during rapid cold-hardening and pupal diapause in the flesh fly, Sarcophaga crassipalpis. J. Insect Physiol. 52, 1073-1082. doi: 10.1016/j.jinsphys. 2006.07.005

Murata, N., and Wada, H. (1995). Acyl-lipid desaturases and their importance in the tolerance and acclimatization to cold of cyanobacteria. Biochem. J. 308, 1-8. doi: 10.1042/bj3080001

Pamplona, R. (2008). Membrane phospholipids, lipoxidative damage and molecular integrity: a causal role in aging and longevity. Biochim. et Biophys. Acta (BBA) Bioener. 1777, 1249-1262. doi: 10.1016/j.bbabio.2008.07.003

Pamplona, R., Portero-Otin, M., Ruiz, C., Gredilla, R., Herrero, A., and Barja, G. (2000). Double bond content of phospholipids and lipid peroxidation negatively correlate with maximum longevity in the heart of mammals. Mech. Ageing Dev. 112, 169-183. doi: 10.1016/s0047-6374(99)00045-7

Pan, D. A., and Storlien, L. H. (1993). Dietary lipid profile is a determinant of tissue phospholipid fatty acid composition and rate of weight gain in rats. J. Nut. 123, 512-519. doi: 10.1093/jn/123.3.512

Peoples, G. E., and McLennan, P. L. (2010). Dietary fish oil reduces skeletal muscle oxygen consumption, provides fatigue resistance and improves contractile recovery in the rat in vivo hindlimb. Br. J. Nut. 104, 1771-1779. doi: 10.1017/ s0007114510002928

Pierce, B. J., McWilliams, S. R., O’Connor, T. P., Place, A. R., and Guglielmo, C. G. (2005). Effect of dietary fatty acid composition on depot fat and exercise performance in a migrating songbird, the red-eyed vireo. J. Exp. Biol. 208, 1277-1285. doi: 10.1242/jeb.01493

Plotkin, M., Ermakov, N. Y., Volynchik, S., Barkay, Z., Bergman, D. J., and Ishay, J. S. (2005). A thermoregulatory center in hornets: ir photography. Microscopy Res. Technique 68, 321-328. doi: 10.1002/jemt.20257

Rodríguez, E., Weber, J.-M., and Darveau, C.-A. (2018). Diversity in membrane composition is associated with variation in thermoregulatory capacity in hymenopterans. Comparat. Biochem. Physiol. Part B Biochem. Mol. Biol. 224, 115-120. doi: 10.1016/j.cbpb.2017.11.017

Rodríguez, E., Weber, J.-M., Pagé, B., Pagé, B., Roubik, D. W., Suarez, R. K., et al. (2015). Setting the pace of life: membrane composition of flight muscle varies with metabolic rate of hovering orchid bees. Proc. R. Soc. B Biol. Sci. 282:20142232. doi: 10.1098/rspb.2014.2232

Ruedenauer, F. A., Raubenheimer, D., Kessner-Beierlein, D., Grund-Mueller, N., Noack, L., Spaethe, J., et al. (2020). Best be (e) on low fat: linking nutrient perception, regulation and fitness. Ecol. Lett. 23, 545-554. doi: 10.1111/ele. 13454

Ruf, T., and Arnold, W. (2008). Effects of polyunsaturated fatty acids on hibernation and torpor: a review and hypothesis American. J. Physiol. Regulatory Integrat. Comparat. Physiol. 294, R1044-R1052.

Ruf, T., Valencak, T., Tataruch, F., and Arnold, W. (2006). Running speed in mammals increases with muscle n-6 polyunsaturated fatty acid content. PLoS One 1:e65. doi: 10.1371/journal.pone.0000065

Rule, D. C. (1997). Direct transesterification of total fatty acids of adipose tissue, and of freeze-dried muscle and liver with boron-trifluoride in methanol Meat. Science 46, 23-32. doi: 10.1016/s0309-1740(97)00008-9

Savage, N., and Goldstone, B. (1965). Effect of different dietary fats on oxygen consumption and on serum lipid levels in the baboon (Papio ursinus). Br. J. Nut. 19, 459-467. doi: 10.1079/bjn19650042

Scharf, I., Filin, I., Golan, M., Buchshtav, M., Subach, A., and Ovadia, O. (2008). A comparison between desert and mediterranean antlion populations: differences in life history and morphology. J. Evol. Biol. 21, 162-172. doi: 10.1111/j.14209101.2007.01453.x
Seeley, T. D. (1989). The honey bee colony as a superorganism. Am. Sci. 77, $546-553$.

Silvius, J. R. (1982). "Thermotropic phase transitions of pure lipids in model membranes and their modifications by membrane proteins," in Lipid-Protein Interactions, Vol. 2 eds P. C. Jost, and O. H. Griffith (New York, NY: John Wiley and Sons, Inc), 239-281.

Simpson, J. (1961). Nest climate regulation in honey bee colonies. Science 133, 1327-1333. doi: 10.1126/science.133.3461.1327

Sprague, M., Dick, J. R., and Tocher, D. R. (2016). Impact of sustainable feeds on omega-3 long-chain fatty acid levels in farmed Atlantic salmon, 2006-2015. Sci. Rep. 6, 1-9. doi: 10.1007/978-3-319-28275-6_80-1

Stabentheiner, A., Kovac, H., and Brodschneider, R. (2010). Honeybee colony thermoregulation-regulatory mechanisms and contribution of individuals in dependence on age, location and thermal stress. PLoS One 5:e8967. doi: 10. 1371/journal.pone.0008967

Stanley-Samuelson, D. W., Jurenka, R. A., Cripps, C., Blomquist, G. J., and de Renobales, M. (1988). Fatty acids in insects: composition, metabolism, and biological significance. Arch. Insect Biochem. Physiol. 9, 1-33. doi: 10.1002/arch. 940090102

Starling, A., East, J., and Lee, A. (1993). Effects of phosphatidylcholine fatty acyl chain length on calcium binding and other functions of the calcium-magnesium-atpase. Biochemistry 32, 1593-1600. doi: 10.1021/bi00057 a025

Stukey, J. E., McDonough, V. M., and Martin, C. E. (1990). The ole1 gene of saccharomyces cerevisiae encodes the delta 9 fatty acid desaturase and can be functionally replaced by the rat stearoyl-coa desaturase gene. J. Biol. Chem. 265, 20144-20149. doi: 10.1016/s0021-9258(17)30481-7

Takeuchi, H., Matsuo, T., Tokuyama, K., Shimomura, Y., and Suzuki, M. (1995). Diet-induced thermogenesis is lower in rats fed a lard diet than in those fed a high oleic acid safflower oil diet, a safflower oil diet or a linseed oil diet. J. Nut. $125,920-925$.

Vonshak, M., and Shlagman, A. (2009). A Camponotus fellah queen sets a record for Israeli ant longevity Israel. J. Entomol. 39:165.

Wallis, J. G., Watts, J. L., and Browse, J. (2002). Polyunsaturated fatty acid synthesis: what will they think of next? Trends Biochem. Sci. 27, 467-473. doi: 10.1016/ s0968-0004(02)02168-0

Wilson, D. S., and Sober, E. (1989). Reviving the superorganism. J. Theor. Biol. 136, 337-356. doi: 10.1016/s0022-5193(89)80169-9

Zhang, J.-L., Zhang, S.-B., Zhang, Y.-P., and Kitajima, K. (2015). Effects of phylogeny and climate on seed oil fatty acid composition across 747 plant species in china. Industrial Crops Products 63, 1-8.

Conflict of Interest: The authors declare that the research was conducted in the absence of any commercial or financial relationships that could be construed as a potential conflict of interest.

Publisher's Note: All claims expressed in this article are solely those of the authors and do not necessarily represent those of their affiliated organizations, or those of the publisher, the editors and the reviewers. Any product that may be evaluated in this article, or claim that may be made by its manufacturer, is not guaranteed or endorsed by the publisher.

Copyright (C) 2021 Volov, Cohen, Bodner, Dubiner, Hefetz, Bouchebti and Levin. This is an open-access article distributed under the terms of the Creative Commons Attribution License (CC BY). The use, distribution or reproduction in other forums is permitted, provided the original author(s) and the copyright owner(s) are credited and that the original publication in this journal is cited, in accordance with accepted academic practice. No use, distribution or reproduction is permitted which does not comply with these terms. 